EREM 77/2

Journal of Environmental Research, Engineering and Management

Vol. 77 / No. 2 / 2021

pp. 63-70

DOI 10.5755/10.5755/j01.erem.77.2.29056
Innovation Ecosystem for Sustainable Business Model Development: Practical Insights

\begin{tabular}{|l|l}
\hline Received 2021/05 & Accepted after revision 2021/06 \\
\hline
\end{tabular}

\title{
Innovation Ecosystem for Sustainable Business Model Development: Practical Insights
}

\section{Žaneta Stasiškiené ${ }^{*}$, Jūratė Petkevičienè}

Kaunas University of Technology, Institute of Environmental Engineering,

Gedimino st. 50, LT-44239 Kaunas, Lithuania

\section{Evelina Meilienè, Rūta Čiutienè}

Kaunas University of Technology, School of Economics and Business,

Gedimino st. 50, LT-44239 Kaunas, Lithuania

*Corresponding author: zaneta.stasiskiene@ktu.lt

The capability to rapidly and successfully move into new business models is an important source of sustainable competitive advantage and a key leverage to improve the sustainability performance place-based innovations of organizations. However, the performed research suggests that many business model innovations fail. Despite the importance of the topic, the reasons for failure are relatively unexplored, and there is no comprehensive review of the successful sustainable business model innovation framework. This paper provides a review of drivers and barriers for sustainable business innovations in the context of ecosystem and its services.

Keywords: sustainable business model, innovation ecosystem, place-based innovations, co-creation.

\section{Introduction}

Both national innovation systems and regional development initiators seek to meet the requirements of an ever-changing global competitive environment. Ecosystems at different levels - national, regional and urban
- are undergoing major structural changes as the economy moves from production to services. The related socio-technical development shapes the principles of innovation creation. In order to manage these structural 
changes and to effectively develop the system of creation and implementation of innovations, it is necessary to link these activities with the sustainable development of the ecosystem.

The newest research shows that innovation is usually driven by a system of factors that can be combined with the concept of ecosystem (Rauter, 2017). Ecosystems can vary in size, including large clusters, cities and regional areas. They usually have innovation centers, such as universities, research institutes and others, which carry out value creation, research and development and patenting activities (Ritala, 2018; Belz, 2017). Without such centers, the creation and optimization of value chains is inconceivable: the more well-known online activities there are, the more talent, companies, and investments an ecosystem attracts (Abdelkafi, 2016). Smart centers are also well placed to respond to an ever-changing environment due to a dynamic innovation-creating ecosystem and interdisciplinarity (Bocken, 2019).

Previous research has emphasized that the creation and development of business innovation requires a special ecosystem consisting of top universities, research institutions with sufficient funding, a skilled workforce, defined specialization, guaranteed cooperation with business and access to global networks (Ritala, 2018). However, only a relatively small number of regions have such a system and potential (Sotarauta, 2017). The present ever-changing spectrum of innovations means that the conditions listed above are sufficient but not necessary for their successful development.

So what could be the minimum selection of factors for successful innovation creation and implementation? Many researchers and stakeholders have raised this issue. As a result, the term "innovation ecosystem" has emerged to mean a dynamic, interactive interdisciplinary network that fosters innovation. Its roots are in industrial and business clusters (lammarino, 2019; Hein, 2020), conceptual development of innovation (e.g., Horne, 2020), and Triple Helix's approach to regional development and national innovation systems (Hein, 2020). Many studies have focused on local and regional ecosystems and their development. Still the efficient framework for sustainable innovation ecosystem is missing. Therefore, the system of the factors that shape a sustainable innovation ecosystem will be discussed in the paper.

\section{Literature Review}

\section{Sustainable innovation ecosystems}

The concept of an innovation ecosystem has gained increased popularity over the last decade, because of its particular link to open innovation. The term was firstly coined by Tansley (Tansley, 1935), to call one ecological element embedding the living creatures and their environment. Presently, the innovation ecosystem comprises a multilayer framework during which institutions interconnect to develop and share information and knowledge required for the innovation processes (Granstrand et al., 2020). It evidences the co-creation and sharing of the stakeholders to produce a coherent solution which satisfy the challenges of the demand.

By their meaning the sustainable innovations work as catalysts for cleaner production, meeting societal challenges in both the short and future, encompassing economic and environmental targets in local and global dimensions. These innovations underpin sustainable development integrating the system approach and relying upon the local and specialized networks, local communities, and company sustainability index (Oksanen, 2015; Adner, 2006). Therefore, it can be stated that the innovation ecosystem is a network of relationships combining actors and objects that establish connections, both complementary and substitute reinforcing the importance of the institutions and also the environment, providing information and knowledge flows through systems important to ensure co-creation and enhance sustainability (Adner, 2006).

A vigorous innovation ecosystem can create for the companies an inspirational innovation environment where they can share creation and testing with a community and stakeholders. This process can include governments, value chain actors, and the user community, which communicate and promote an innovation (Boons, 2013). The above-mentioned processes can be reinforced by openness and adaptableness, enlarging participation to unusual partners to get the knowledge arising from the quintuple helix.

Innovative activities are not restricted within a single player borders anymore as they appear to be a component of broader interaction with the environment, involving various players embedded within an interdependent 
innovation ecosystem (Zeng, 2017). Establishment of organized interactions favours the continuity of the ecosystem, which should be settled on trust, sharing, and a meaningful sense of identity that consolidate the network supported shared values, which enhance sustainable practices (Zeng, 2017; Ding, 2018). Recent theoretical developments like Reynolds and Uygun (Reynolds, 2018; Uygun, 2018) argue that inside modern ecosystems there is a high level of interaction between key players like universities, the value chain actors, and thus the user community to create innovative capabilities. Shifting from value chains to ecosystems is more likely in organizations adopting industry 4.0 frameworks, service, or customer orientations as they are emerged in networked ecosystems; still, this movement involves changes within the business model and increasing enrolment with stakeholders (Chesbrough, 2007; Liu, 2019).

The existence of solid community networks with different roles and interests generates mutual challenges requiring sustainable practices to uphold the ecosystem.

\section{The place-based innovations}

The place-based approach has been emerging because of the new paradigm for local and regional development. The approach elicits several key dimensions, such as: an identification and mobilization of endogenous potential; the popularity of the expansion potential across all places; strong and adaptable local institutions; local ownership and wide stakeholder engagement (Tomaney, 2010). Consistent with Barca et al. (2012), two fundamental aspects of the place-based approach are the following: first, it accounts for a geographical context, in terms of social, cultural, and institutional characteristics, in a very manner that "matters"; and second, it focuses on the problem of information in policy intervention.

Some defining features of the dominant place-based narrative are as follows:

Identification of underutilized potential in an exceeding region to boost regional competitiveness and addressing social exclusion;

Focus on functional economic areas;

Institutional structures to higher account for relational territories;

Strengthened leadership and collaborative governance capacity;
They must pool resources, including private sector actors as co-creators.

Place-based narratives have helped to re-affirm that place matters because it highlights the importance of understanding the role of regional hierarchies and their influence on the potential for the event of the assets in an exceeding locality and potential development paths. Therefore, the attributes of the place-based innovation system are as follows:

1 It ensures the creation of the policies to support under-served populations. In many local areas, there are certain social groups that are excluded. Creating or upholding policies that support minority groups can help to access underutilized talent and spur growth.

2 It identifies the economic areas that have the potential for growth within the particular community. As past research has shown, regional ecosystems develop alongside specific sectors. Additional growth can come from supporting specific sectors during a region.

3 It supports and creates developments that are relevant to the local population. It is important to form institutions that match the wants of the community before investing the time and capital to make and develop them.

4 It strengthens the link between community, government, and business leaders. A well-developed network between and within different sectors in an exceeding community is important for all healthy entrepreneurship ecosystems.

5 It pools resources between private actors. Within an innovation ecosystem, growth comes from the ecosystem society investing in up-and-coming innovators.

\section{Methodology}

For the analysis, the methodology of the 7 dimensions of innovation ecosystems 4.0 was used. The essence of it is the last-generation environments for "Innovation Ecosystems 4.0":

1 innovation ecosystems may be virtual, but they need to be grounded in real-life hubs;

2 innovation ecosystems should be transversal and multidimensional; 
3 innovation ecosystems should be open and connected;

4 innovation ecosystems should avoid centralization and rethink governance;

5 innovation ecosystems should actively develop tools and methods to better collaborate;

6 innovation ecosystems should be ethical and straight;

7 innovation ecosystems should have a shared sense of direction, meaning and values.

The innovation ecosystems bringing together these various characteristics could function like huge "living labs". By adding distributed technology for sharing ideas and tracing authorship and merit, these living labs could become the cornerstone of innovation ecosystems 4.0.

\section{Results and Discussion}

\section{Importance of the ecosystem approach: theoretical considerations}

Biologically, the term ecosystem refers to the system of living organisms and non-living physical components, linked together through complex cycles and energy flows. In a business context, we can apply similar structure there diverse participants are linked by information and value flows. This architecture is represented by the dynamic ways of thinking around how ideas can create meaningful shared value for members of the ecosystem. This can ensure that dynamic changes of market forces, new collaborative technologies, and emerging new business models will be evaluated systematically.

The defining characteristics of a sustainable innovation ecosystem are mutuality and orchestration. In contrast to a market that operates primarily according to the laws of simple supply and demand, ecosystem entities operate out of mutual self-interest. No matter which or even how many of these organizing structures the ecosystem actors belong to, they exist in an ecosystem where participants believe that they can create and receive more value acting together within the ecosystem than apart.

Also, comparable to nutrient and energy flows in a biological ecosystem, actors of a sustainable innovation ecosystem participate in coordinated interactions and value exchanges in the ecosystem. These activities can occur through informal cultural mores, through more formal rules, or through the facilitating activities of an orchestrator.

\section{Co-creation for sustainable musiness model development engaging local stakeholders: practical experience from international project}

The project "European Life Science ecosystems" (ELISE) project was selected for the research due to the high level of complexity and diversity of stakeholders.

The ELISE combines regional ecosystem development and interregional cooperation. It covers a vast range of research and industrial areas of application. One region is unlikely to have all necessary skills, knowledge and facilities to address today's sustainable region issues. Through partner exchange, the projects' approach evolved to address the main phases of ecosystem support. As a secondary objective, it assesses feasibility of long-term creation of a European ecosystem for innovations.

The partners elaborated ELISE in a climate of cooperation and exchange. Bilateral meetings were held for exchange with the partners' experience. They provided information on regional contexts: needs, experiences and stakeholders. They shared the understanding of thematic context and its state of the art. Together they defined the most suitable approach to reach objectives. This laid the basis for productive co-operation, designed to meet the needs of the regions involved.

A qualitative research design was used to examine the phenomena of co-creation as a tool to involve stakeholders in project outcome value development. A focus group discussion was conducted in order to collect data.

ELISE addresses a recognized societal challenge: to promote sustainable wellbeing for all in the region. At European level, this challenge is articulated into the need to improve health and wellbeing outcomes and promote healthy and active ageing, as well as to promote market growth, job creation, to promote the EU as a global sustainability leader and reduce the burden of wellbeing problems on individuals, health and care systems and society.

Each partner had an opportunity to learn the best good practice (GP) examples from other partners during the visits. The best GP examples were evaluated according to the following criteria:

Relevance with respect to the local context (number of beneficiaries taking advantage from the GP, 
how long the GP has been in operation; amount of public budget invested, etc.);

Impact: new initiatives or projects stemmed from the GP (for example, complementary actions, new revised and improved measures); level of satisfaction of the beneficiaries/actors involved;

Innovation degree: how new was the approach introduced by the GP (have you already heard of similar initiatives carried out in other contexts/ regions?);

Networking improvements: impacts to the regional eco-system/capacity of involvement of different stakeholders/community effect/spillover effects in national and/or transnational context;

Sustainability: the intrinsic value and equitable endurance of natural and human systems in the present and the future, based on unified characteristics of decision-making about and processes of production, consumption, resource use, waste, and ecological systems;

Transferability: to what extent is the GP strictly connected to the framework conditions in which it has been developed? Would it be easy to apply in another regional context?

Each partner presented from 2 to 4 GP examples for the evaluation and the best of them were chosen to share at the EU level.

According to the project idea - to learn from the best existing experiences - the staff exchange was performed by each partner: there was a possibility to visit and get a deeper view into the existing GP examples.

Based on the experience gained, the Action Plans were developed by the partners.

Seven action plans were developed containing from one to three actions:

1 Kaunas University of Technology. Action 1 - Development of a co-creation hub to build the life science ecosystem. The main goal of such a center will be to ensure the fluid co-operation and knowledge distribution between different Kaunas city's stakeholders, Kaunas city municipality and government of Lithuania.

2 ART-ER Consortium (ASTER). Action 1 - Methodology to elaborate strategic projects. The first action will be directed towards identifying mechanisms to ensure the elaboration of projects of strategic relevance for the territory of the Region. It will be articulated in two com- ponents: the elaboration of a methodology for identifying and generating strategic projects, and the elaboration of a fully-fledged project. Action 2 - Development of a strategic test project. The methodology elaborated in the previous Activity 1.1 will be then tested through the preparation of an actual strategic project.

3 Cassovia Life Sciences/Košice Self-governing region. Action 1 - Supporting clusters via calls for proposals. The main goal of the action is to create a call from Slovak ERDF focused on the clusters. Action 2 - Improving tools for innovation in companies. The main goal of the action is to adjust SPARK methodology to the needs of company-based workshops. Action 3 - Improving RIS3 of Košice region. The main goal of this action is focused on improvement suggested RIS3 strategy.

4 Lubelskie Voivodeship. Action 1 - NLAB acceleration program. NLAB Acceleration Bridge - a program focused on knowledge transfer and internationalization of businesses - was created in connection with ELISE GP SPARK. Action 2 - R\&D mobility program-EDP phase. The goal of this strategic program is to make a better use for founding research and innovation (Lubelskie Regional Operational Programme, Axis 1 Research \& Innovation), strengthen the R\&l system, and incorporate the region into global innovation chain knowledge transfer.

5 CentreVal de Loire Regional Council. Action 1 - Fostering the dialogue between the public laboratories and companies in order to induce projects with a higher economic impact. This method is a tool aiming at fostering the dialogue between companies and research by empowering researchers to think about research results from a market point-based view on the business model canvas (BMC) to improve the marketability of research-based products and services. Action 2 - Improving the governance of the Research and Innovation Strategy (RIS) specializationz domain in order to increase coherence and synergies between projects. The action consists in empowering a governing body, with the mission to construct a strategy and a roadmap of projects in the Biotechnology and applied services for health domain, and to monitor and evaluate these projects, both on an individual and a global level.

6 BioCon Valley Mecklenburg Vorpommern e.V. Action 1 - Widening of an existing funding scheme to implement life science projects up to a higher Tech- 
nical Readiness Level (TRL) with industry alike equipment though process innovation. The existing funding scheme Directive on the promotion of research, development and innovation of the Ministry of Economy, Employment and Health has been adapted and extended. The new funding status allows applying for investments as a follow-up of process innovations.

7 Life Science Nord. Action 1 - "LSN Innovate!" - Education program for manageable risks in innovative life science projects. "LSN Innovate!" will organize the regional innovation experts and the regional innovation actors from the whole value chain.

The project contributed to all EU2020 strategy principles, as it joins local innovation and a global challenge. By focusing on the innovative sustainability field, ELISE particularly responds to the Smart Growth goal to develop an economy based on knowledge and innovation. By linking this to a sustainable region, ELISE contributes to the Innovation Union aim of refocusing R\&D and innovation policy on the challenges society faces, as well as addresses the problem of fragmented R\&l efforts among EU countries and regions. By analyzing the ecosystems and proposing actions for their creation, ELISE offers a concrete answer to this issue: the solutions can, therefore, only be found through co-operation between different sectors of the innovation chain (public authorities, enterprises, academia, civil society) at regional and interregional level. Partners have recognized the need for collaborative approaches. They have also recognized the need to exchange ideas, experiences and practical approaches to creating and running sustainable regions, using a quadruple helix model that groups public authorities, business, researchers and end users; it promotes multidisciplinary and cross sector collaboration.

ELISE leads to short, medium and long-term results. Participating regions will be able to better support the sustainability related sectors and the enterprises operating around it to use the project results and to create places of work. In the long term, this should contribute to creating healthy, competitive and innovative European regions.

\section{Innovation ecosystem: theoretical framework}

Oosterbroek et al. (2016) have pointed that the relationship between the ecosystem and health has a strong interaction with socio-economic factors. However, it is needed to stress that the essential socio-economic dimension processes are interdependent and dependent on the culture, politics and organizations (Laurans, 2014). The specific political tasks related to the social economy, such as economic growth, employment, financial returns, wealth creation are needed to be solved (Spash, 2015). Therefore, it can be stated that in order to build a new regional ecosystem, the role of the government and regional public authorities cannot be auxiliary, as it is the case with creation of the clusters. According to Casper (2013), the government role is not the primary catalyst in creating a successful cluster, that role is only supportive for the creation of research and encouraging its translation and commercialization. However, as creation of the regional life sciences for the healthcare and wellbeing ecosystems in different free EU countries shows, the government of a country and regional public authorities have the direct influence and play the central role in shaping an ecosystem of this nature. The common economic, social, political situation in a country is dependent on the government and it is influenced by the regional public authorities. Therefore, the regional public authorities are expected to be important actors, which could join the regional clusters for the move to the unified regional ecosystem. Therefore, the understanding of future challenges, collaboration and conversation among such institutions is the important factor defining how quickly different countries will create such a type of ecosystems and will solve future problems. A simplified model to move from the created regional clusters to a unified co-creation life science for the healthcare and wellbeing ecosystem is presented in Fig.1.

The creation of such a type of ecosystems at the regional level could be guided by the presented model. The carried-out investigation in three different EU countries (Poland, Italy, Germany) has confirmed this assumption.

The Poland Lubelskie region has named the Lubelskie Voivodeship the Managing Authority and set it in charge of the Regional Innovation Strategy. The local government units play the main role as coordinators or the ones that are responsible for the regional innovation strategy while creating of the ecosystem. Additionally, the Lublin Science and Technology Park - a company dependent on the Lubelskie Voivodeship - plays the 
Fig. 1. The simplified model to move from the created regional clusters to a co-creation life science for the healthcare and wellbeing ecosystem

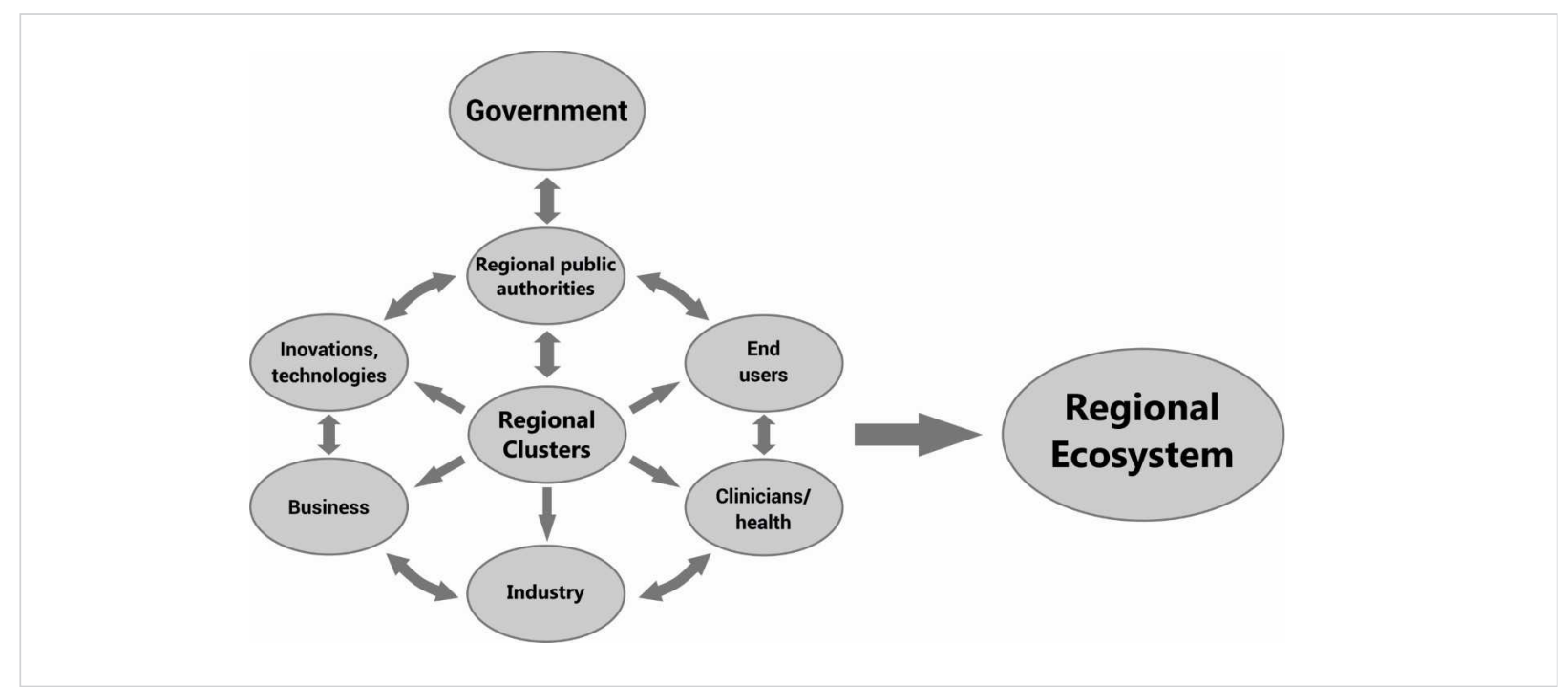

key role in the ecosystem as a facilitator of knowledge transfer to the market.

In the Italian Emilia-Romagna region, the Regional Government (Managing Authority) together with ASTER have played an important role in creating the health and wellness industrial innovation ecosystem. The Regional Government is the majority stakeholder of the innovation agency ASTER and it is also the managing authority for the selected policy instrument. The Emilia-Romagna Health Regional Agency influences the policy instrument by providing its extensive knowledge in the planning, design and monitoring phases. However, Labour and Enterprise Department and Healthcare Department have to improve the alignment on policy instruments and strategic objectives, even if integrations have been put in place, at an operative level among academies, hospitals and industries.

The state government of the German Mecklenburg-Vorpommern region as of the beginning is the main participant and plays the main role in creating, developing and shaping the life sciences' ecosystem in this region. The state government's initiative has commissioned the Master Plan Health Economy 2020 and has created the Board of Trustees for Health Economy. The Board of Trustees is setting the strategic direction with ministers, university directors, state secretaries, entrepreneurs, representatives of the public health sector and other stakeholders. However, according to the German
Mecklenburg-Vorpommern region's practice, the work of such a board of trustees can only be successfully implemented with the reliable support at the political level. Simultaneously, it is necessary to make financial resources available at the national level and set up a project office. It is also important that a carefully prepared action plan forms the basis for the work. In addition, the establishment of such a board makes sense only if the central economic factor of the region is at the center of attention and the work is planned for a long period of time. It is the only possibility to implement strategic goals in practice. If all these conditions are met, such an instrument is an excellent prerequisite for the implementation of strategic objectives of the region. It is of an enormous importance that a balanced composition of the board is ensured. In particular, participation of industry representatives plays the substantial role in ensuring that the needs of the economy are met, thus creating added value for the region.

The central role in shaping the unified regional ecosystem directly depends on the regional public authorities. Therefore, there is a need to improve the collaboration with such institutions which can help and improve the implementation of regional development policies and programs, in particular the programs for investment in Growth and Jobs and, where relevant, ETC programs that support the delivery of innovation by actors in regional innovation chains in areas of smart specialization and innovation opportunity. 


\section{References}

Abdelkafi, N., Täuscher, K. (2016) Business models for sustainability from a system dynamics perspective. Organization \& Environment, 29(1), 74-96. Available at: https://doi. org/10.1177/1086026615592930

Adner, R. (2006) Match your innovation strategy to your innovation ecosystem. Harv. Bus. Rev., 84, 98-107.

Barca, F., McCann, P. and Rodriguez-Pose, A. (2012) The case for regional development intervention: Place-based versus place-neutral approaches. Journal of Regional Science, 52(1), 134-152 https://doi.org/10.1111/j.1467-9787.2011.00756.x

Belz, F. M., Binder, J. K. (2017) Sustainable entrepreneurship: A convergent process model. Business Strategy and the Environment, 26(1), 1-17. Available at: https://doi.org/10.1002/bse.1887

Bocken, N., Boons, F., Baldassarre, B. (2019) Sustainable business model experimentation by understanding ecologies of business models. Journal of Cleaner Production, 208, 1498-1512. Available at: https://doi.org/10.1016/j.jclepro.2018.10.159

Boons, F.; Luedeke-Freund, F.(2013) Business models for sustainable innovation: State-of-the-art and steps towards a research agenda. J. Clean. Prod., 45, 9-19. https://doi.org/10.1016/j.jclepro.2012.07.007

Casper S. (2013) New-technology clusters and public policy: Three perspectives. Soc Sci Inform 52(4):628-652. Available at: https://doi.org/10.1177/0539018413501236

Chesbrough, H., Schwartz, K. (2007). Innovating business models with co-development partnerships. Res. Technol. Manag., 50, 55-59. https://doi.org/10.1080/08956308.2007.11657419

Ding, L., Wu, J. (2018) Innovation ecosystem of CNG vehicles: A case study of its cultivation and characteristics in Sichuan, China. Sustainability, 10 (1), 39. https://doi.org/10.3390/su10010039

Granstrand, O., Holgersson, M. (2020) Innovation ecosystems: A conceptual review and a new definition. Technovation, 90, 102098. https://doi.org/10.1016/j.technovation.2019.102098

Hein, L., Bagstad, K. J., Obst, C., Edens, B., Schenau, S., Castillo, G., Soulard, F., Brown, C., Driver, A., Bordt, M., Steurer, A., Harris, R., Caparrós, A. (2020) Progress in natural capital accounting for ecosystems. Science, 367(6477), 514-515. https:// doi.org/10.1126/science.aaz8901

Horne, J., Recker, M., Michelfelder, I., Jay, J., Kratzer, J. (2020) Exploring entrepreneurship related to the sustainable development goals - Mapping new venture activities with semi-automated content analysis. Journal of Cleaner Production, 242, 118052. https://doi.org/10.1016/j.jclepro.2019.118052

lammarino, S., Rodriguez-Pose, A. and Storper, M. (2019) Regional inequality in Europe: Evidence, theory and policy implications. Journal of Economic Geography, 19, 273-298. https://doi. org/10.1093/jeg/lby021
Laurans Y, Mermet L (2013) Ecosystem services economic valuation, decision-support system or advocacy? Eco Serv 7:98105. https://doi.org/10.1016/j.ecoser.2013.10.002

Liu, Z.; Stephens, V. (2019) Exploring innovation ecosystem from the perspective of sustainability: Towards a conceptual framework. J. Open Innov. Technol. Market Complex, 5, 48. https://doi.org/10.3390/joitmc5030048

Moore, J. (1993) Predators and prey: A new ecology of competition. Harv. Bus. Rev., 71, 75-86.

Oksanen, K.; Hautamäki, A. (2015) Sustainable innovation: A competitive advantage for innovation ecosystems. Technol. Innov. Manag. Rev., 5, 24-30. https://doi.org/10.22215/timreview934

Oosterbroek B., Kraker Joop, Huynen MMTE, Martens P. (2016) Assessing ecosystem impacts on health: A tool review. Eco Serv 17:237-254. Available at: https://doi.org/10.1016/j.ecoser.2015.12.008

Rauter, R., Jonker, J., Baumgartner, R. J. (2017) Going one's own way: Drivers in developing business models for sustainability. Journal of Cleaner Production, 140(Pt. 1), 144-154. Available at: https://doi.org/10.1016/j.jclepro.2015.04.104

Reynolds, E.; Uygun, Y. (2018) Strengthening advanced manufacturing innovation ecosystems: The case of Massachusetts. Technol. Forecast. Soc. Chang., 136, 178-191. https://doi.org/10.1016/j. techfore.2017.06.003

Ritala, P., Huotari, P., Bocken, N., Albareda, L., Puumalainen, K. (2018) Sustainable business model adoption among S\&P 500 firms: A longitudinal content analysis study. Journal of Cleaner Production, 170, 216-226. Available at: https://doi. org/10.1016/j.jclepro.2017.09.159

Sotarauta, M., Beer, A. \& Gibney, J. (2017) Making sense of leadership in urban and regional development. Regional Studies, 51(2), 187-193. https://doi.org/10.1080/00343404.2016.1267340

Spash CL, Aslaksen L (2015) Re-establishing an ecological discourse in the policy debate over how to value ecosystems and biodiversity. J environ management 159:245-253. Available at: https://doi.org/10.1016/j.jenvman.2015.04.049

Tansley, A.G. (1935) The use and abuse of vegetational concepts and terms. Ecology, 16, 284-307. https://doi.org/10.2307/1930070 Tomaney, J. (2010) Place-Based Approaches to Regional Development: Global Trends and Australian Implications. A report for the Australian Business Foundation November 2010

Zeng, D.; Hu, J.; Ouyang, T. (2017) Managing innovation paradox in the sustainable innovation ecosystem: A case study of ambidextrous capability in a focal firm. Sustainability, 9, 2091. https://doi.org/10.3390/su9112091 